\title{
TRATAMIENTO DE LA INFERTILIDAD ENDOCRINA Y DE LAS DISFUNCIONES MENSTRUALES CON ENOVID
}

\author{
Doctor Maxwell Roland
}

Los nuevos compuestos progestacionales orales sintéticos han venido a proporcionarnos agentes terapéuticos de gran valor para la corrección de algunas de las causas de la infertilidad. Enovid, uno de esos esteroides sintéticos, ejerce un efecto especial sobre el endometrio humano, distinto del producido por las hormonas naturales. La acción de este compuesto sobre los cuatro componentes histológicos principales del endometrio, glándulas, epitelio, estroma y vasos sanguíneos, es diferente en cada uno de ellos. La terapia de veinte días con Enovid, iniciada al comienzo del ciclo, irá a producir un desarrollo avanzado del estroma hasta llegar al estado predecidual, entre tanto que las glándulas quedarán estacionadas en la fase proliferativa temprana. El epitelio y los vasos sanguíneos también se desarrollan en grado menos marcado que el estroma. Esta acción es debida a ciertas propiedades que son inherentes al Enovid. Además de su marcado efecto progestacional posee también una actividad estrogénica asociada que le da a este compuesto la propiedad de mantener el endometrio en un estado que semeja el embarazo. Ninguna combina- ción de los esteroides ováricos naturales, estrógenos y progesterona, puede imitar estos resultados. Este fenómeno hace de este compuesto una droga única en su clase, y la cual puede ser usada con gran utilidad en ciertos desórdenes que causan infertilidad, tales como amenorrea secundaria, fase luteínica corta $o$ insuficiente y hemorragia uterina disfuncional.

La capacidad que tiene el Enovid para inhibir la ovulación ha venido a usarse como fenómeno de rebote en aquellas pacientes con ciclos anovulatorios. La infertilidad idiopática, que puede manifestarse a sí misma en forma de oligomenorreas e hipomenorreas, evitando en esa forma el embarazo, también puede beneficiarse con la terapia con Enovid. La mayor parte del conocimiento que nosotros tenemos hoy día acerca de estos compuestos sintéticos se ha venido acumulando luego de su uso empírico en forma casi exclusiva. En el momento actual, y debido a la falta de información precisa sobre el mecanismo metabólico de los esteroides en general, nosotros solamente podemos especular acerca del más probable "modus operandi" de estos progestágenos. 
Gracias a los muchos y variados efectos benéficos obtenidos, nosotros podemos anticipar un gran esfuerzo hacia la creación de compuestos esteroides sintéticos designados a ejercer acciones fisiológicas específicas.

\section{USOS CLINICOS DEL ENOVID}

Ciclos anovulatorios. Se considera una paciente como anovulatoria si durante tres ciclos consecutivos se logra comprobar en ella algunas o todas las siguientes características: temperatura basal monofásica persistente, ausencia endometrio secretor premenstrual, persistencia de cristalización típica en helecho del moco cervical y ausencia excreción premenstrual de pregnandiol. Estas pacientes reciben Enovid, 10 mgm. diarios a partir del cuarto día del ciclo hasta el 24o día. Terminada la menstruación, que aparece a los pocos días de suspendida la droga, ésta es repetida durante tres ciclos consecutivos. Aproximadamente $15 \%$ de esas pacientes ovulan cuando se interrumpe la terapéutica en los dos a cuatro meses siguientes. En nuestra experiencia $10 \%$ de ellas generalmente conciben.

2. Amenorrea secundaria. Cuando este trastorno se asocia a la infertilidad, las pacientes pueden exitosamente ser tratadas con Enovid. Es importante que el diagnóstico adecuado sea hecho antes de iniciar el tratamiento. El estudio previo debe incluír una biopsia endometrial que muestre el tipo de endometrio. Estudio de los niveles de $17 \mathrm{ce}$ tosteroides, 17 hydroxy-progesterona y pregnanetriol en orina de 24 horas. Los síndromes adrenogenitales y de Stein-
Leventhal deben ser descartados, y cuando estos últimos se diagnostiquen, no deben ser tratados con progestágenos.

El Enovid, debido a su propiedad innata de acción estrogénica así como progestacional, puede ser de invaluable utilidad en el tratamiento de pacientes con amenorrea secundaria. Ciento cincuenta miligramos de Enovid en dosis fraccionada $(10 \mathrm{mgm}$. diarios) producirán hemorragia por deprivación en el $80 \%$ de los casos, siempre y cuando la paciente tenga alguna secreción endógena de estrógenos. En caso de no producirse la hemorragia por deprivación en tres a cuatro días después de interrumpir la terapia, puede ser entonces necesario el preparar el endometrio con estrógeno adicional, tal como el Etinil-estradiol, $0.05 \mathrm{mgm}$. tres veces al día, por quince días, seguido de Enovid, 10 mgm. diarios por 10 a 15 días. Este esquema de tratamiento debe ser repetido por al menos tres ciclos consecutivos. Un porcentaje de las enfermas así tratadas revelarán signos de ovulación y concebirán después de dicho tratamiento.

3. Fase luteínica corta o insuficiente. El mejor método de diagnóstico de esta anomalía es por medio de la temperatura basal y del endometrio premenstrual. La gráfica de temperatura basal demostrará una fase luteínica corta y/o insuficiente, la última por medio de un efecto termógeno irregular. El endometrio revelará actividad secretora inicial $o$ insuficiente en la biopsia inmediatamente premenstrual. Este trastorno se encuentra en cierto porcentaje de pacientes con infertilidad idiopática, las cuales con frecuencia son abortadoras 
habituales. Dichas enfermas se les prescribe $10 \mathrm{mgm}$. diarios de Enovid del $16^{\circ}$ al $26^{\circ}$ día del ciclo. Si no se presenta hemorragia tres a cuatro días más tarde, se debe asumir que existe un embarazo, y entonces se debe continuar el Enovid por tres meses más. Un test biológico de embarazo debe hacerse después de los 14 días del período echado de menos, con el objeto de evitar un diagnóstico errado de embarazo. En el caso de existir anormalidad del zigote, la paciente abortará a pesar de cualquier tratamiento. Cuando se presentan pequeñas hemorragias genitales durante el tratamiento con Enovid se debe tener presente la posibilidad de un aborto retenido y se debe entonces repetir los test biológicos de embarazo. La terapia progestínica no se debe comenzar antes del día $16^{\circ}$, con el objeto de evitar la interferencia con la función normal del cuerpo lúteo. En ocasiones las glándulas endometriales se hacen quísticas si se comienza el tratamiento con Enovid inmediatamente después de la ovulación.

4. Hemorragia uterina disfuncional. El Enovid produce un estroma semejante al del embarazo temprano. Esta gran actividad progestacional mantiene el endometrio y por lo tanto evita la hemorragia durante el tratamiento. Después que el raspado uterino ha descartado la patología tumoral endometrial, fibromas submucosos, pólipos y otras anormalidades anatómicas, las pacientes con hemorragia uterina disfuncional pueden recibir Enovid, $30 \mathrm{mgm}$. diariamente por 4 a 5 días para establecer hemostasis, y pueden continuar con $10 \mathrm{mgm}$. diarios por un período mínimo de tres meses. Cuando llegare a presentarse hemorragia durante el tratamiento, la dosis de Enovid debe aumentarse a 30 mgm. diarios hasta que la hemorragia desaparezca y entonces continuar nuevamente con $10 \mathrm{mgm}$. como dosis diaria de mantenimiento. Al final de tres, cuatro o cinco meses (depende de la gravedad del caso), se permite la he- morragia por deprivación. Aproximadamente el $70 \%$ de las pacientes volverán a tener ciclos normales luego de este tratamiento. Ocasionalmente nosotros hemos tenido que tratar pacientes hasta por 9 o 10 meses antes de poder establecer ciclos normales. No se presentaron reacciones secundarias ni cambios endometriales anormales luego de tratamientos tan prolongados. Muchos úteros, especialmente en pacientes iniciando la menopausia, pueden ser salvados de ser extirpados mediante dicho tratamiento.

5. Infertilidad idiopática. Esta se presenta en forma de oligomenorrea o hipomenorrea después de ciclos ovulatorios. Estas pacientes merecen un tratamiento con Enovid en forma cíclica, $10 \mathrm{mgm}$. diarios del $5^{\circ}$ al $25^{\circ}$ día por dos a tres ciclos. Nos satisfizo el que algunas de estas pacientes concibieran y tuvieran niños normales después de haberse sometido a dicha terapéutica.

\section{COMENTARIO}

La acción selectiva del Enovid sobre los cuatro componentes del endometrio difiere de la imagen histológica carácterística del endometrio normal menstrual. Es por lo tanto de importancia el no usar standards convencionales pa- 
ra describir los cambios endometriales obtenidos con el Enovid y debiéndose describir en forma separada la imagen histológica de cada uno de los cuatro componentes endometriales principales.

El Enovid administrado cíclicamente por 20 días, evita el embarazo. Esto puede deberse a inhibición hipofisaria, haciendo al endometrio hostil para la nidación, o por medio de cambios en el moco cervical que eviten la migración del espermatozoide. La hemorragia por deprivación causada por el Enovid en pacientes con amenorrea secundaria, se debe aparentemente a su inherente actividad progestacional así como estro- génica. El fenómeno de rebote observado en pacientes con ciclos anovulatorios puede ser debido posiblemente al período de descanso dado a los ovarios y/o a la hipófisis. La capacidad del Enovid para mantener la integridad del estroma y vascularización endometrial por un período prolongado de tiempo, hace de esta droga un elemento de valor en el tratamiento de la hemorragia uterina disfuncional y en los desórdenes de fase luteal corta o insuficiente. Los nuevos compuestos progestacionales han sido de gran valor y se harán aún más importantes como ayudas para aliviar algunos de los trastornos productores de infertilidad. 